Article

\title{
Phytosynthesis of Palladium Nanoclusters: An Efficient Nanozyme for Ultrasensitive and Selective Detection of Reactive Oxygen Species
}

\author{
Ravi Mani Tripathi ${ }^{1,2}$ and Sang J. Chung ${ }^{1, * \mathbb{C}}$ \\ 1 School of Pharmacy, Sungkyunkwan University, 2066 Seoburo, Jangan-gu, Suwon, Gyeonggido 16419, Korea; \\ rmtripathi02@gmail.com \\ 2 Amity Institute of Nanotechnology, Amity University Uttar Pradesh, Sector 125, Noida 201303, India \\ * Correspondence: sjchung@skku.edu; Tel.: +82-31-290-7703; Fax: +82-31-292-8800
}

Academic Editor: Alireza Ghiasvand

Received: 29 June 2020; Accepted: 21 July 2020; Published: 23 July 2020

\begin{abstract}
Hydrogen peroxide is a low-reactivity reactive oxygen species (ROS); however, it can easily penetrate cell membranes and produce highly reactive hydroxyl radical species through Fenton's reaction. Its presence in abnormal amounts can lead to serious diseases in humans. Although the development of a simple, ultrasensitive, and selective method for $\mathrm{H}_{2} \mathrm{O}_{2}$ detection is crucial, this remains a strategic challenge. The peroxidase mimetic activity of palladium nanoclusters (PdNCs) has not previously been evaluated. In this study, we developed an ultrasensitive and selective colorimetric detection method for $\mathrm{H}_{2} \mathrm{O}_{2}$ using PdNCs. An unprecedented eco-friendly, cost-effective, and facile biological method was developed for the synthesis of PdNCs. This is the first report of the biosynthesis of PdNCs. The synthesized nanoclusters had a significantly narrow size distribution profile and high stability. The nanoclusters were demonstrated to possess a peroxidase mimetic activity that could oxidize peroxidase substrate 3,3',5,5'-tetramethylbenzidine (TMB). Various interfering substances in serum $\left(100 \mu \mathrm{M}\right.$ phenylalanine, cysteine, tryptophan, arginine, glucose, urea, $\mathrm{Na}^{+}, \mathrm{Fe}^{2+}$, $\mathrm{PO}_{4}{ }^{3-}, \mathrm{Mn}^{+2}, \mathrm{Ca}^{2+}, \mathrm{Mg}^{2+}, \mathrm{Zn}^{2+}, \mathrm{NH}_{4}{ }^{+}$, and $\mathrm{K}^{+}$) were included to evaluate the selectivity of the assay, and oxidation of TMB occurred only in the presence of $\mathrm{H}_{2} \mathrm{O}_{2}$. Therefore, PdNCs show an efficient nanozyme for the peroxidase mimetic activity. The assay produced a sufficient signal at the ultralow concentration of $0.0625 \mu \mathrm{M} \mathrm{H}_{2} \mathrm{O}_{2}$. This colorimetric assay provides a real-time, rapid, and easy-to-use platform for the detection of $\mathrm{H}_{2} \mathrm{O}_{2}$ for clinical purposes.
\end{abstract}

Keywords: palladium nanoclusters; nanozyme; peroxidase mimetic activity; colorimetric detection; hydrogen peroxide; 3,3',5,5'-tetramethylbenzidine

\section{Introduction}

Enzymes are frequently used to catalyze the conversion of biomolecules; however, they require mild conditions to facilitate the reaction. In contrast, chemical catalysts can easily facilitate reactions under harsh conditions, such as high pressures, high temperatures, organic solvents, and extreme $\mathrm{pH}[1,2]$. Enzymes are extensively used in industry, medical, and biological fields owing to their substrate specificity and high catalytic activities. However, enzymes have some inherent limitations, such as high preparation and purification costs, low operational stability, sensitivity to environmental conditions, and difficulties in recycling and reuse [3]. To overcome these limitations, researchers are exploring the possibility of developing artificial enzyme mimics that are cost-effective and have high stability. Several studies have explored the development of artificial enzyme (also called nanozyme [3]) mimic materials, such as $\mathrm{ZnO}-\mathrm{Pd}$ nanosheets [4], $\mathrm{Fe} 3 \mathrm{O} 4$ nanoparticles [5], $\mathrm{Cu}-\mathrm{Ag}$ on graphene oxide [6], and metal-organic 
frameworks [7]. These nanozymes have enzyme mimetic activity and are widely used for the oxidation of peroxidase substrate 3,3',5,5'-tetramethylbenzidine (TMB) for the detection of $\mathrm{H}_{2} \mathrm{O}_{2}$.

The three main reactive oxygen species (ROS) are hydrogen peroxide, superoxide, and hydroxyl radicals, which are normal products of cellular metabolism [8]. $\mathrm{H}_{2} \mathrm{O}_{2}$ is a low-reactivity molecule; however, it can actively penetrate cell membranes and produce the most reactive form of oxygen, that is, hydroxyl radicals, through Fenton's reaction $\left(\mathrm{H}_{2} \mathrm{O}_{2}+\mathrm{Fe}^{2+} \rightarrow \mathrm{Fe}^{3+}+\mathrm{OH}^{-}+\mathrm{OH} \bullet\right)$ [9]. An abnormal production of $\mathrm{H}_{2} \mathrm{O}_{2}$ can lead to oxidative stress, which is the main contributor to aging [10] and leads to serious diseases such as diabetes [11], cancer [10], and neurodegenerative Alzheimer's and Parkinson's diseases [12,13]. Furthermore, $\mathrm{H}_{2} \mathrm{O}_{2}$ is a potential molecule for various clinically important applications. The most widespread use of $\mathrm{H}_{2} \mathrm{O}_{2}$ is for the oxidation of peroxidase chromogenic substrates to detect biological molecules. Hence, it is important to develop not only an effective nanozyme to replace the enzyme, but also a highly sensitive and selective method for the detection of $\mathrm{H}_{2} \mathrm{O}_{2}$. This provides the motivation for developing an effective nanozyme for peroxidase mimetic activity as well as a highly sensitive and selective colorimetric detection method for $\mathrm{H}_{2} \mathrm{O}_{2}$. We previously developed an ultrasensitive and selective colorimetric detection method for lead [14]. We previously reported the biosynthesis of triangular and hexagonal gold nanoparticles [15], palladium nanoparticles [16-18], and HAp nanofibers [19]. The present study reports the biosynthesis of nanoclusters.

In this study, we developed an eco-friendly, simple, and cost-effective method for the synthesis of palladium nanoclusters (PdNCs) using phytochemicals (plant extracts). To the best of our knowledge, no nanoclusters have been exploited for peroxidase mimetic activity thus far. Furthermore, we have not found previous reports on the use of PdNCs as nanozymes. The biosynthesized nanoclusters exhibited ultrasensitive and selective detection of $\mathrm{H}_{2} \mathrm{O}_{2}$. The novelty of the reported method for the detection of $\mathrm{H}_{2} \mathrm{O}_{2}$, in comparison with previously reported methods, is presented in a tabulated form in Table 1 [20-33]. The biosynthesis of palladium nanoclusters in itself is a novel achievement, and no reports are available on the use of biological methods for this purpose.

Table 1. Comparison of various reported methods for $\mathrm{H}_{2} \mathrm{O}_{2}$ detection.

\begin{tabular}{cccc}
\hline Detection Mode & $\begin{array}{c}\text { Detection } \\
\text { Limit }\end{array}$ & $\begin{array}{c}\text { Operating } \\
\text { Time }\end{array}$ & Ref. \\
\hline Gold nanoparticle-based colorimetric biosensor assay & $1 \mu \mathrm{M}$ & $15 \mathrm{~min}$ & {$[20]$} \\
$\mathrm{Fe}_{2}\left(\mathrm{MoO}_{4}\right)_{3}$ micromaterial-MMT-based colorimetric assay & $0.7 \mu \mathrm{M}$ & $400 \mathrm{~s}$ & {$[21]$} \\
Au nanocluster-based fluorescence assay & $0.2 \mu \mathrm{M}$ & $8 \mathrm{~min}$ & {$[22]$} \\
Magnetic mesoporous silica nanoparticle-based colorimetric assay & $4.0 \mu \mathrm{M}$ & $20 \mathrm{~min}$ & {$[23]$} \\
$\mathrm{MnO}_{2}$ nanosheet-modified UCNP-based fluoroimmunoassay & $0.9 \mu \mathrm{M}$ & $40 \mathrm{~min}$ & {$[24]$} \\
Ag S-MMT-based colorimetric assay $_{\text {Fluorescent NS-carbon quantum dots }}$ & $19.16 \mu \mathrm{M}$ & $21 \mathrm{~min}$ & {$[25]$} \\
TPE-BO-based fluoroimmunoassay & $4.0 \mu \mathrm{M}$ & $10 \mathrm{~min}$ & {$[26]$} \\
CD-NP-BE-based fluoroimmunoassay & $0.52 \mu \mathrm{M}$ & $15 \mathrm{~min}$ & {$[27]$} \\
Silver nanoparticles for colorimetric detection & $0.5 \mu \mathrm{M}$ & $60 \mathrm{~min}$ & {$[28]$} \\
Ag-coated TFBG-SPR assay & $0.09 \mu \mathrm{M}$ & $60 \mathrm{~min}$ & {$[29]$} \\
Silver nanoparticle-based colorimetric assay & $0.2 \mu \mathrm{M}$ & $20 \mathrm{~min}$ & {$[30]$} \\
ZnO nanoparticles & $5.0 \mu \mathrm{M}$ & $40 \mathrm{~min}$ & {$[31]$} \\
Bimetallic metal-organic framework of the type MOF (Co/2Fe) & $5.0 \mu \mathrm{M}$ & & {$[32]$} \\
Biosynthesized palladium nanocluster-based colorimetric assay & $0.0625 \mu \mathrm{M}$ & $20 \mathrm{~min}$ & {$[33]$} \\
\hline
\end{tabular}

\section{Results and Discussion}

\subsection{UV/Vis Analysis}

The biosynthesis of PdNCs was determined by measuring their absorbance as a function of time after the addition of leaf extract to the palladium chloride solution. Erigeron Canadensis L. leaf extract was used as the reducing and capping agents for the synthesis of nanoclusters (Figure 1a). The peak observed at $420 \mathrm{~nm}$ for the palladium chloride aqueous solution indicated the presence of 
$\mathrm{Pd}^{2+}$ ions. This peak almost disappeared after the synthesis of the nanocluster (Figure $1 \mathrm{~b}$ ) and the amount of PdNC was estimated based on the amount of the used $\mathrm{PdCl}_{2}$. The formation of nanoclusters was monitored at different time intervals $(0,5,15,30,60,90$, and $180 \mathrm{~min})$ by scanning the UV/Vis absorbance spectra of the samples. Figure $1 \mathrm{~d}$ shows the impact of the incubation time on the color of the reaction mixture. As soon as the leaf extract was added to the aqueous solution of palladium chloride, the color intensity increased until an incubation time of $150 \mathrm{~min}$. However, after $180 \mathrm{~min}$ of incubation, no color change was observed visually. The UV/Vis spectra show that the absorbance increased with increasing incubation time, but the increase was minimal after 180 min compared with that at $150 \mathrm{~min}$ (Figure 1b). Changes in the absorbance spectra at $400 \mathrm{~nm}$ as a function of time and stationary phase were observed after $150 \mathrm{~min}$ (Figure 1c). Therefore, the optimum reaction time was found to be $150 \mathrm{~min}$.
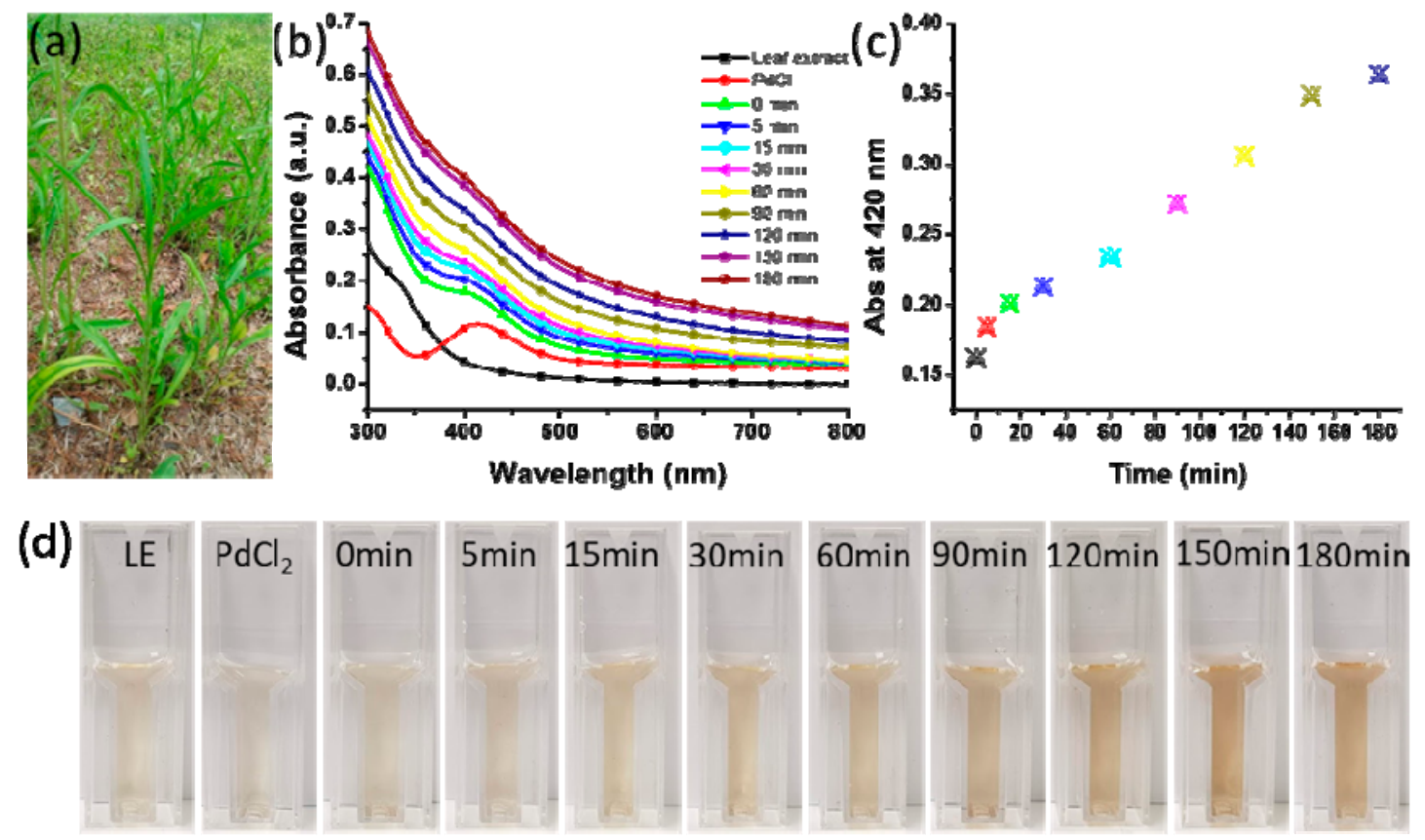

Figure 1. Biosynthesis of palladium nanoclusters (PdNCs): (a) Erigeron canadensis L.; (b) UV/Vis spectra of the leaf extract, palladium chloride, and biosynthesis of PdNCs; (c) Absorbance at $400 \mathrm{~nm}$ as a function of time; (d) The impact of incubation time on the color of reaction mixture (LE: leaf extract).

\subsection{Dynamic Light Scattering (DLS) Analysis}

The synthesized nanoclusters were analyzed by DLS to determine the size distribution profile. The size distribution results indicate that the nanoclusters had a Z-average diameter of $64.47 \mathrm{~nm}$ (Figure S1). Particles sized $<100 \mathrm{~nm}$ are considered useful for various applications owing to their surface-to-volume ratios. In addition, particles of $<100 \mathrm{~nm}$ can effortlessly cross the plasma membrane cells for different types of applications. The stability of nanoparticles is also an important consideration for various applications. The polydispersity index is dimensionless and scaled such that values smaller than 0.05 are generally observed with highly monodisperse standards, whereas those greater than 0.7 show that the sample has a significantly wide particle size distribution [34]. The synthesized nanoclusters exhibited a polydispersity index of 0.053 , indicating monodispersion. It has been reported that the polydispersity index must be less than 0.7 for good quality nanomaterials [35].

\subsection{Transmission Electron Microscopy (TEM) Analysis}

The morphology, size, and crystalline nature of the synthesized PdNCs were determined using TEM. Various magnifications were used to obtain the micrographs to better elucidate the nature of the nanoclusters (Figure 2). The Z-average diameter of the synthesized nanoclusters was determined 
to be $64.47 \mathrm{~nm}$ in the DLS analysis (Figure S1), whereas the TEM analysis indicated a diameter of approximately $57 \mathrm{~nm}$, because the DLS showed the hydrodynamic size of the nanostructures. The TEM micrographs show that the synthesized nanoclusters had a significantly narrow size distribution of 28-76 nm (Figure 2a,b). The size distribution histogram shows that the synthesized clusters have a significantly narrow size distribution, ranging from 28 to $76 \mathrm{~nm}$. The histogram also shows that the average nanocluster belongs to $57 \mathrm{~nm}$ (inset in Figure $2 \mathrm{~b}$ ). The inset in Figure $2 \mathrm{c}$ shows an enlarged image of a single nanocluster, revealing that significantly small particles combined to form the nanoclusters. The high-resolution TEM (HR-TEM) results show that the nanoclusters exhibited the lattice-fringe characteristic of crystalline materials. The inset of Figure $2 \mathrm{~d}$ shows these lattice fringes, clearly revealing the crystalline nature of the nanoclusters; the inter-atomic spacing (d-spacing) was determined to be $0.22 \mathrm{~nm}$. Few reports have been published for the chemical synthesis of PdNCs, but all of these syntheses required chemicals that increase the production cost as well as create environmental problems [36,37]. The method proposed in this study is simple, rapid, cost-effective, environmentally friendly, and requires no hazardous chemicals. Furthermore, the results show that the developed method could successfully synthesize nanoclusters of good quality. The nanoclusters were characterized three months after synthesis, and no agglomeration/aggregation was observed, confirming the stability of the nanoclusters. The stability of the nanoclusters was further analyzed by sonicating the colloidal solution of nanoclusters, and the resulting TEM micrographs showed no notable influence of mechanical shaking on the nanoclusters (Figure S2). DLS analysis was done after sonication of as-synthesized nanoclusters. The Z-average of as-synthesized nanoclusters is found to be $64.47 \mathrm{~nm}$. After sonication, the Z-average changes to $67.44 \mathrm{~nm}$ with broad peaks (Figure S3). Therefore, sonication has significantly little impact on the size of nanoclusters, which shows that the synthesized nanoclusters are stable.

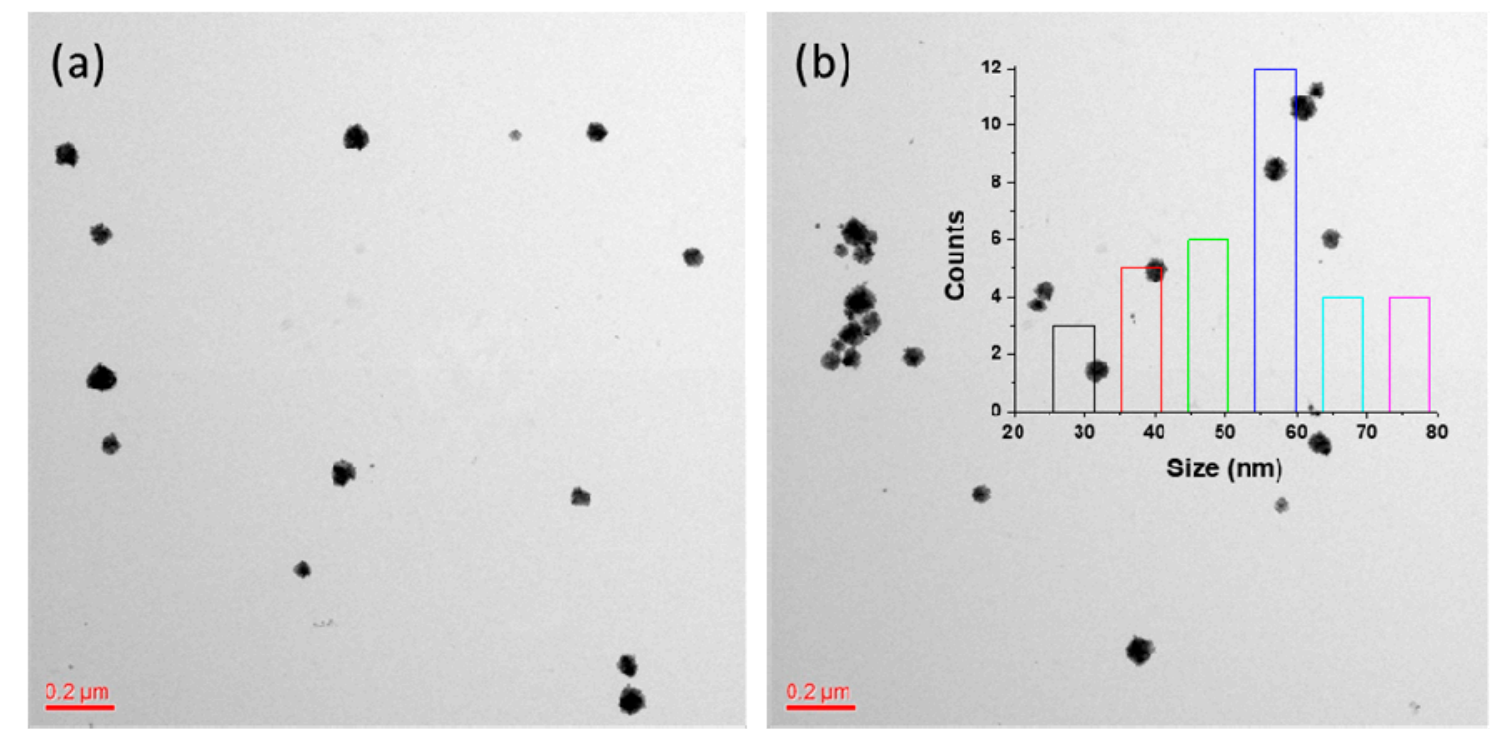

Figure 2. Cont. 

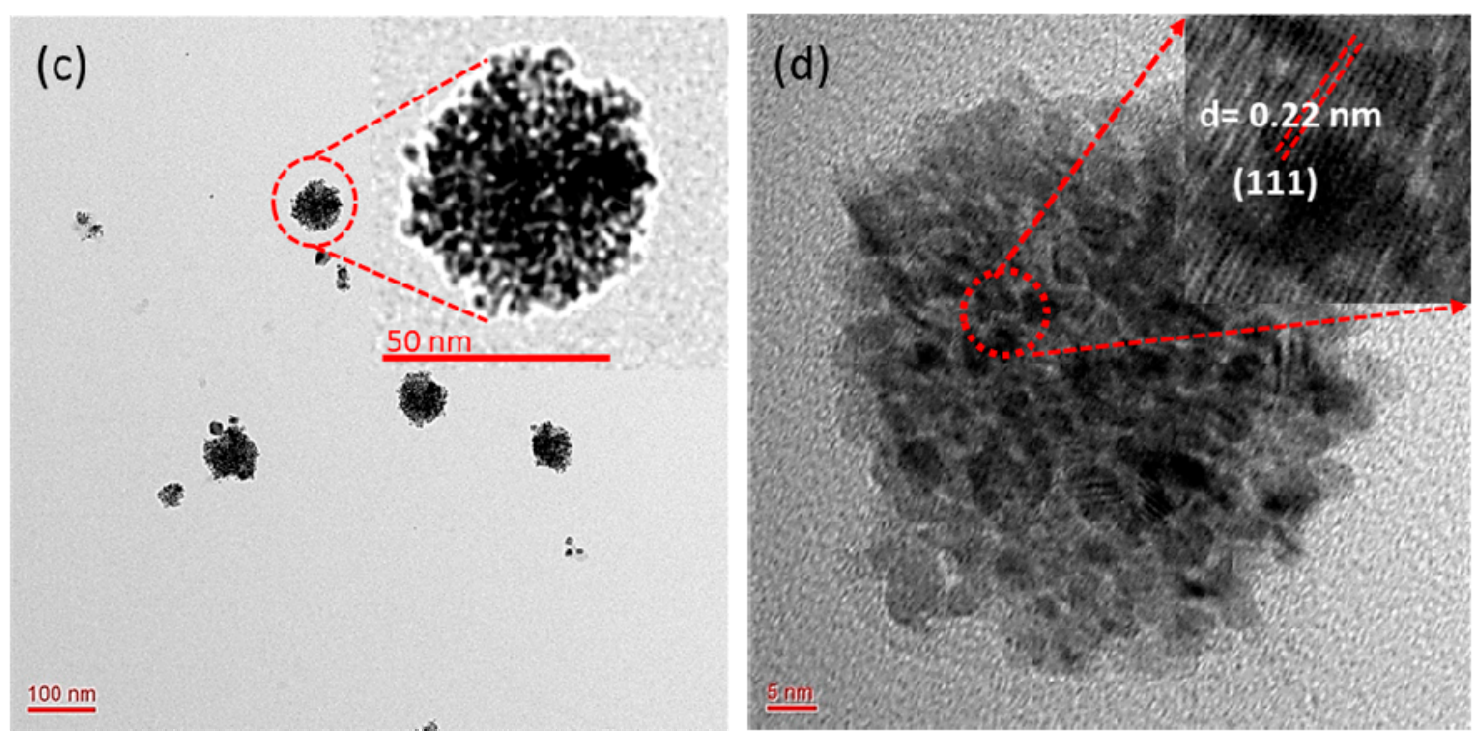

Figure 2. Transmission electron microscopy (TEM) micrographs of the PdNCs at different magnifications: (a) Wide scan of the sample at $0.2 \mu \mathrm{m}$ for an overall view; (b) Uniformity of the nanoclusters at low magnification, the inset shows the nanoclusters size distribution histogram; (c) Scan focused on a small area of the sample in which the inset shows a zoomed-in view of a single nanocluster; (d) High resolution (HR)-TEM image showing the crystalline nature of the nanoclusters in which the inset shows the inter-atomic spacing (d-spacing).

\subsection{Selected Area Electron Diffraction (SAED) and X-Ray Diffraction (XRD) Analysis}

The selected area electron diffraction (SAED) pattern of the synthesized PdNCs shows the crystalline nature of nanoclusters. The SAED results also indicate the presence of rings corresponding to the (111), (200), (220), (311), and (222) planes of palladium with a face-centered cubic structure (Figure 3a). These planes were further analyzed by XRD using powdered samples of PdNCs obtained by freeze drying the colloidal solution. The XRD pattern of the PdNCs exhibited distinct reflections at $2 \theta$ of $40.05^{\circ}, 46.59^{\circ}, 68.10^{\circ}, 82.03^{\circ}$, and $86.59^{\circ}$, which corresponded to the (111), (200), (220), (311), and (222) lattice planes of a face-centered cubic (fcc) lattice, respectively (Figure 3b). These reflections are characteristic of the fcc structure of Pd (JCPDS NO: 87-0641). The reflection at $40.02^{\circ}$ (111) is the most intense compared with the other reflections, which indicates the preferred direction for the growth of nanocrystals [37]. A reflection at a $2 \theta$ of $33.59^{\circ}$ was also observed in addition to the reflections belonging to PdNCs, which may be a result of residual moieties of the leaf extract [38]. The Debye-Scherrer formula was used to estimate the crystalline size of PdNCs:

$$
\mathrm{D}=\mathrm{K} \lambda / \beta \cos \theta
$$

where $\beta$ is the full-width at half maximum of the diffraction peaks, $\theta$ is Bragg's diffraction angle, $K=0.9$ is the Scherrer constant or the shape factor, and $\lambda$ is the wavelength of $\mathrm{Cu}-\mathrm{K} \alpha$. The crystallite size of PdNCs was estimated to be $12.66 \mathrm{~nm}$ using the diffraction peak associated with crystal plane (111). 

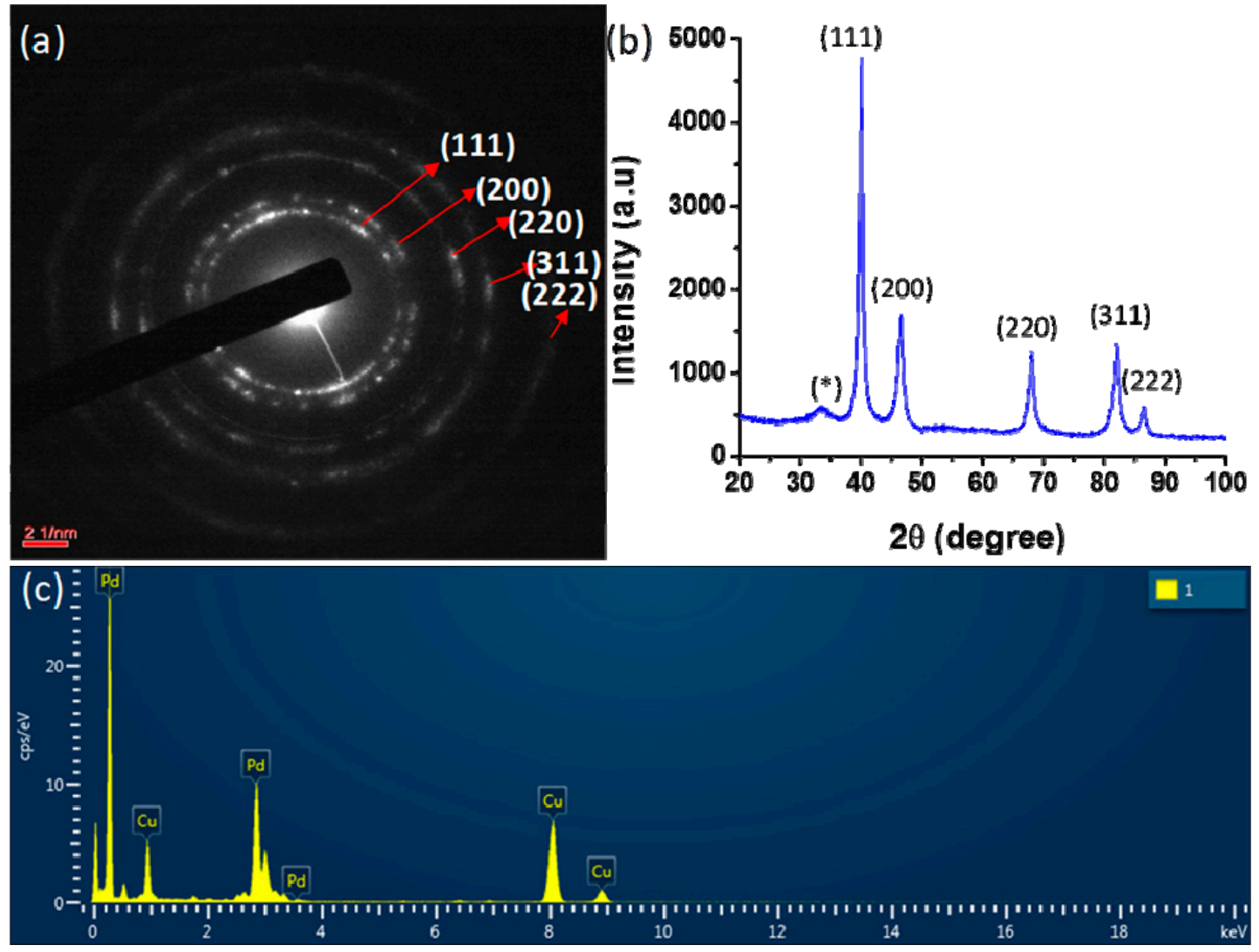

Figure 3. Biosynthesized PdNCs: (a) Selected area electron diffraction (SAED) pattern showing the presence of rings corresponding to the crystalline nature of nanoclusters; (b) X-ray diffraction (XRD) pattern ( ${ }^{*}$ the reflections due to residual moieties of the leaf extract); and (c) Energy-dispersive X-ray spectroscopy (EDX) spectrum exhibiting the signal for elemental palladium.

\subsection{Energy-Dispersive X-Ray Spectroscopy (EDX) and X-Ray Photoelectron Spectroscopy (XPS) Analysis}

The purity of the biosynthesized nanoclusters was determined by evaluating their elemental composition via TEM with EDX. The imaging ability of the microscope allowed the selection of the specimen of interest. The EDX spectrum was obtained in terms of the X-ray counts (cps/eV) versus energy $(\mathrm{keV})$. A strong signal for elemental palladium is present in the EDX spectrum, showing the purity of the biosynthesized nanoclusters (Figure 3c). The spectrum also shows a signal for elemental copper because a copper grid was used for sample preparation. The spectrum includes only elemental palladium and copper, with no other elemental signals observed, indicating the purity as well as the synthesis of the palladium nanoclusters. Table S1 lists the detailed EDX analysis results in terms of the elemental compositions, elemental percentages, series, and $\mathrm{k}$ factors.

The oxidation state of the biosynthesized nanoclusters was determined using XPS. The sample for the XPS analysis was prepared by drying the colloidal solution of nanoclusters on a glass plate. The XPS spectrum shows a peak at a binding energy of $335.22 \mathrm{eV}$, which is the characteristic binding energy of Pd (0) (Figure 4). This clearly indicates that the biosynthesized nanoclusters were zero-valent. 


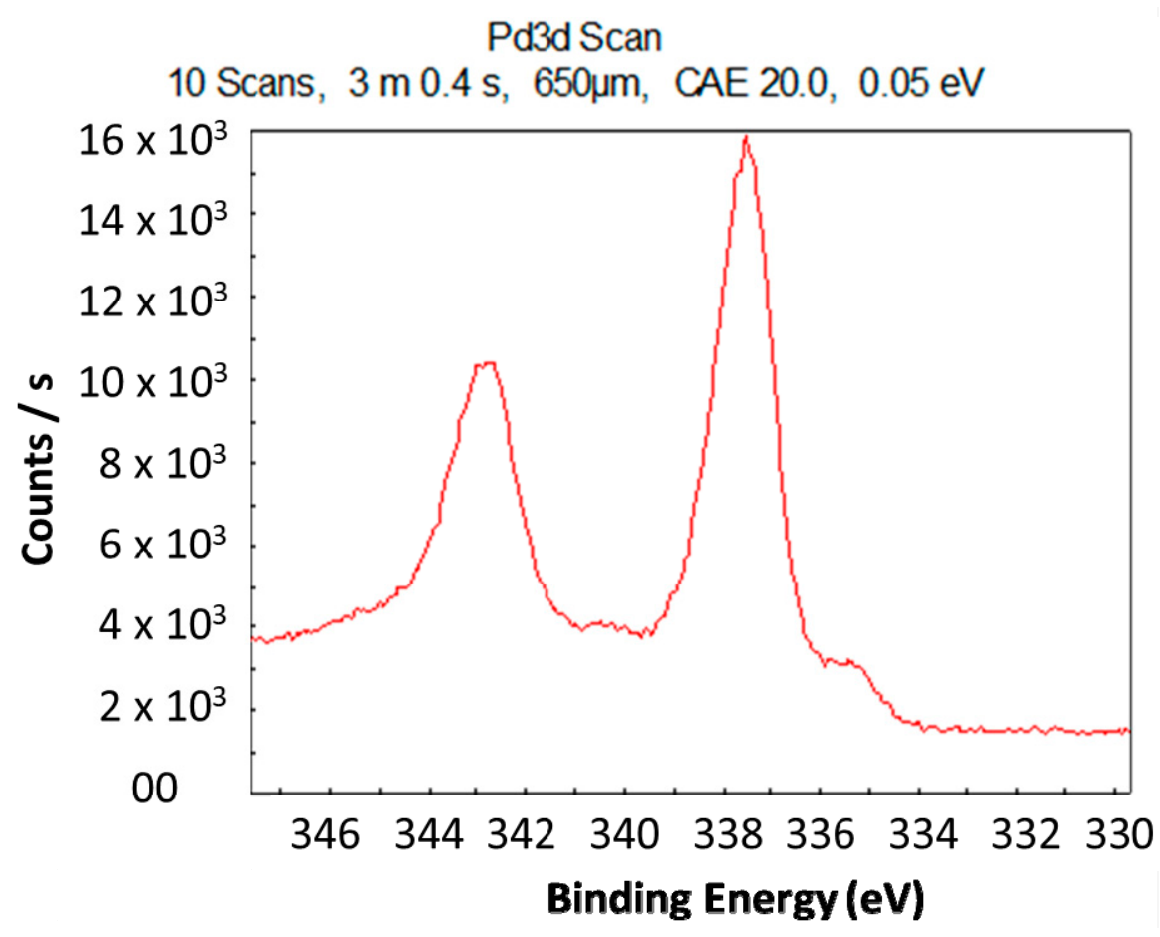

Figure 4. X-ray photoelectron spectroscopy (XPS) spectrum indicating the binding energy of Pd (0).

\subsection{Fourier Transform Infrared (FTIR) Analysis}

The nanoclusters were scanned in the range of $500-4000 \mathrm{~cm}^{-1}$ to elucidate the participation of biological molecules originating from the leaf extract (Figure 5). The FTIR spectrum of the leaf extract includes a peak at $3450.56 \mathrm{~cm}^{-1}$. This particular peak has broadened and shifted to $3431.27 \mathrm{~cm}^{-1}$ in the spectrum of PdNCs, indicating-OH stretching. The leaf extract spectrum shows a peak at $2939.44 \mathrm{~cm}^{-1}$, which corresponds to $\mathrm{C}-\mathrm{H}$ stretching of $\mathrm{CH}_{2}$ and $\mathrm{CH}_{3}$. This peak has shifted to $2956.80 \mathrm{~cm}^{-1}$ in the spectrum of the PdNCs, suggesting the participation of $\mathrm{C}-\mathrm{H}$ stretching vibration in the biosynthesis of PdNCs. The peak shift between particular functional groups of the leaf extract and nanoclusters indicates a reduction and stabilization of nanoclusters [39].

The peak at $1649.09 \mathrm{~cm}^{-1}$ in the leaf extract spectrum shifted to $1652.02 \mathrm{~cm}^{-1}$ in the spectrum of the PdNCs, which corresponds to the stretching vibration of $\mathrm{COO}^{-}$. The leaf extract spectrum also exhibits a peak at $1450 \mathrm{~cm}^{-1}$, which shifted to $1462.0 \mathrm{~cm}^{-1}$ in the PdNCs' spectrum, corresponding to the $\mathrm{N}-\mathrm{H}$ stretching vibration in the amide linkages of the protein. The peak at $1271.05 \mathrm{~cm}^{-1}$ present in the leaf extract spectrum, corresponding to the C-N stretching of amines, is not observed in the PdNCs' spectrum [40]. The leaf extract and PdNCs' spectra contain peaks at 1089.75 and $1045.39 \mathrm{~cm}^{-1}$, respectively, representing a slight shift. These peaks are analogous to that at $1074 \mathrm{~cm}^{-1}$, corresponding to the presence of flavanones adsorbed on the surface of the nanoclusters. This indicated that the structure of flavanones is affected as a result of binding with nanoclusters [39]. 


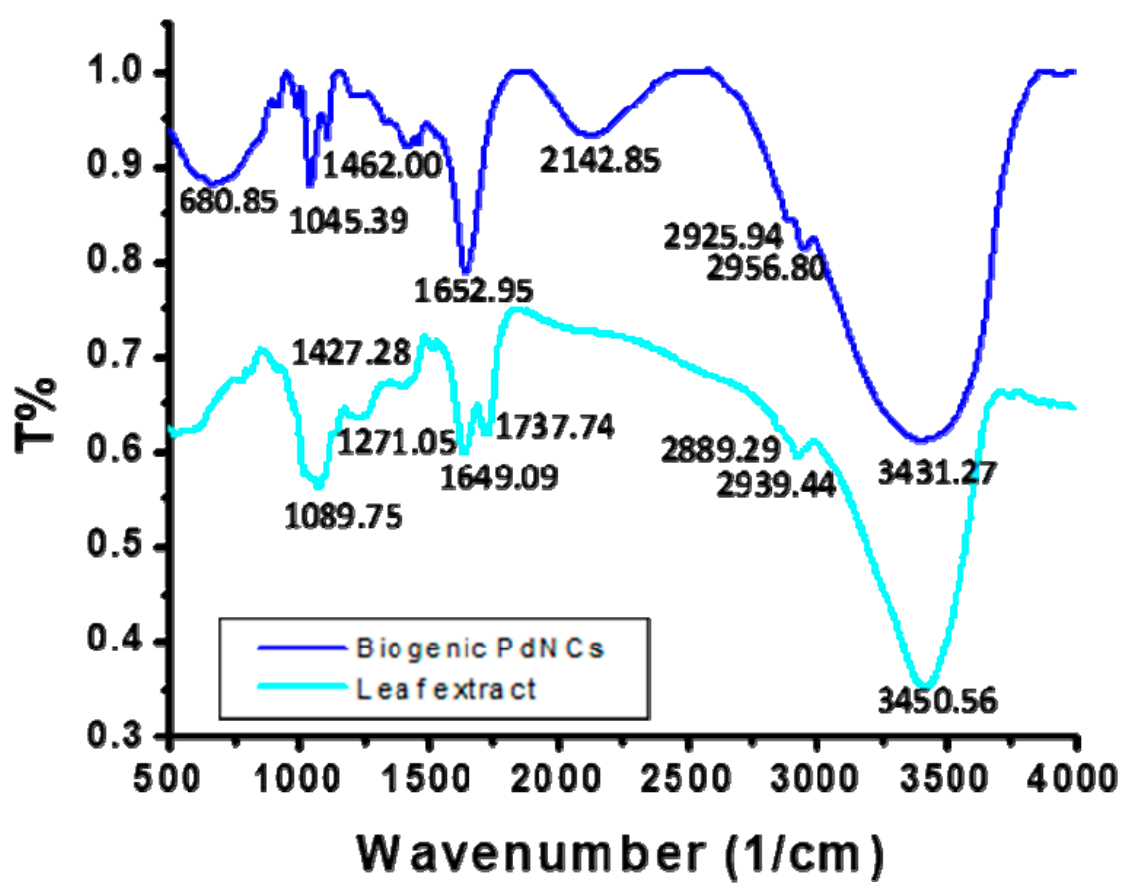

Figure 5. Fourier transform infrared (FTIR) spectra of the Erigeron Canadensis L. leaf extract and as-synthesized PdNCs.

\subsection{Biosynthesis Mechanism}

Erigeron species has been used to cure indigestion, enteritis, hematuria, and epidemic hepatitis [41]. Erigeron species is a rich source of $\gamma$-pyranone derivatives, flavonoids, and phenolic acids [42,43], which play a significant role in the synthesis of nanomaterials. The aqueous solution of E. Canadensis $\mathrm{L}$. leaf extract was used as a reducing and capping agent for the synthesis of PdNCs.

The possible biosynthesis mechanism of PdNCs is developed on the basis of UV/Vis spectroscopy, FTIR, XPS, TEM, and EDX. All parts of the plant are rich in polyphenolic compounds, which actively participate in neutralizing the impact of ROS. High antioxidative properties were shown by flavonoids and tannins present in the aqueous extract of the E. Canadensis L. leaf. Reduction of $\mathrm{Pd}^{2+}$ to $\mathrm{Pd}^{0}$ by polyphenolic compounds occurred when the leaf extract was added to the palladium chloride solution. The color of the reaction solution changed as a function of time, which was monitored by UV/Vis spectroscopy (Figure 1). The complete reduction of $\mathrm{Pd}^{2+}$ into $\mathrm{Pd}^{0}$ took $150 \mathrm{~min}$ to incubate. Subsequently, the neutralized $\mathrm{Pd}^{0}$ experienced nucleation, which produced significantly small-sized nanoparticles. Finally, these particles took the shape of clusters via non-covalent bonding to stabilize (Figure 2). Furthermore, the biomolecules present in the leaf extract covered the surface of the nanocluster and provided high stability. The FTIR illustrated that a peak at $1649.09 \mathrm{~cm}^{-1}$ in the spectrum of the leaf extract shifted to $1652.02 \mathrm{~cm}^{-1}$ in PdNCs, which corresponds to the stretching vibration of $\mathrm{COO}^{-}$(Figure 5). Another peak at $1450 \mathrm{~cm}^{-1}$ in the leaf extract shifted to $1462.0 \mathrm{~cm}^{-1}$ in PdNCs, corresponding to the N-H stretching vibration in the amide linkages of the protein. The peaks at $1089.75 \mathrm{~cm}^{-1}$ (leaf extract) and $1045.39 \mathrm{~cm}^{-1}$ (PdNCs) are analogous to that at $1074 \mathrm{~cm}^{-1}$, corresponding to the presence of flavanones adsorbed on the surface of the nanoclusters. These peaks evidently demonstrate the role of biomolecules in the synthesis of nanoclusters. However, more experimental analyses would be required to understand the comprehensive biosynthesis mechanism.

\subsection{Effect of PdNCs' Concentrations}

Additions of as-synthesized nanoclusters of 2-100 $\mu \mathrm{L}$ were considered to analyze the impact of the concentration of PdNCs on the oxidation of TMB. Figure 6a shows that the color intensity of the assay solutions increased with an increase in the concentration of nanoclusters; however, above 
$50 \mu \mathrm{L}(0.0125 \mathrm{mg} / \mathrm{mL})$ of as-synthesized PdNCs, the color of the assay solutions changed to light green with a blue color. All the samples were scanned with a UV/Vis spectrophotometer to obtain the absorbance spectra for determination of the optimum concentration. Figure $6 \mathrm{c}$ shows the spectra for the assays with different concentrations of nanoclusters. The absorbance at $650 \mathrm{~nm}$ increased rapidly with increasing concentration of PdNCs; however, with the addition of greater than $20 \mu \mathrm{L}$ of as-synthesized nanoclusters, the absorbance value increased little up to the addition of $50 \mu \mathrm{L}$ (Figure 6d). Thereafter, the absorbance decreased with an increase in concentration resulting from the addition of more than $50 \mu \mathrm{L}$ of PdNCs. We also analyzed the impact of the synthesized nanoclusters using the freeze-dried powder of PdNCs in the concentration range from 0.02 to $12 \mathrm{mg} / \mathrm{mL}$ (Figure 6e,f). High concentrations of nanoclusters were applied, but the absorbance was much higher for the case of the as-synthesized nanoclusters with ultralow concentrations. The reason behind the low oxidation of TMB was determined from the SEM micrograph. The micrograph shows that a certain amount of nanoclusters became agglomerated and lost their morphology; however, some amount still retained their small size, as observed in the SEM micrographs (Figure 6b). We thus conclude that a smaller size of nanoclusters with ultralow concentration was effective to achieve high oxidation of TMB. Furthermore, we ran a control assay without $\mathrm{H}_{2} \mathrm{O}_{2}$ and observed that, as the concentration of nanocluster increased, the control assay color intensity also increased because the nanoclusters themselves have a color (Figure S4). Hence, the experimental results indicate that $10 \mu \mathrm{L}(0.0025 \mathrm{mg} / \mathrm{mL})$ of as-synthesized nanoclusters is effective for the oxidation of $0.525 \mathrm{mM}$ TMB.

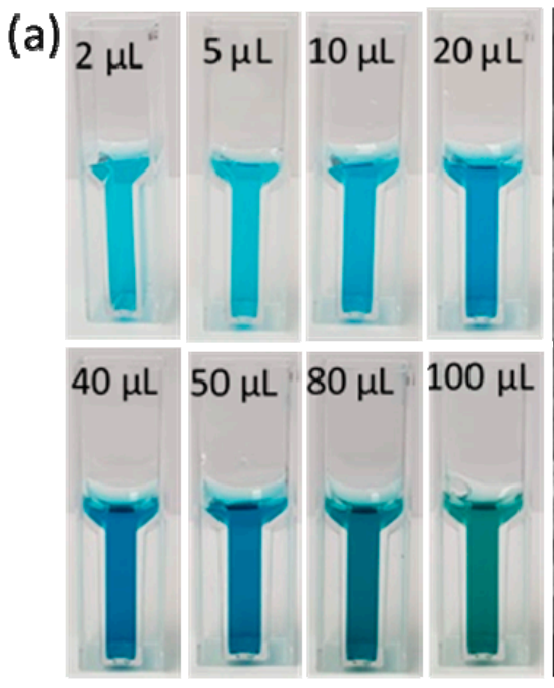

(c)

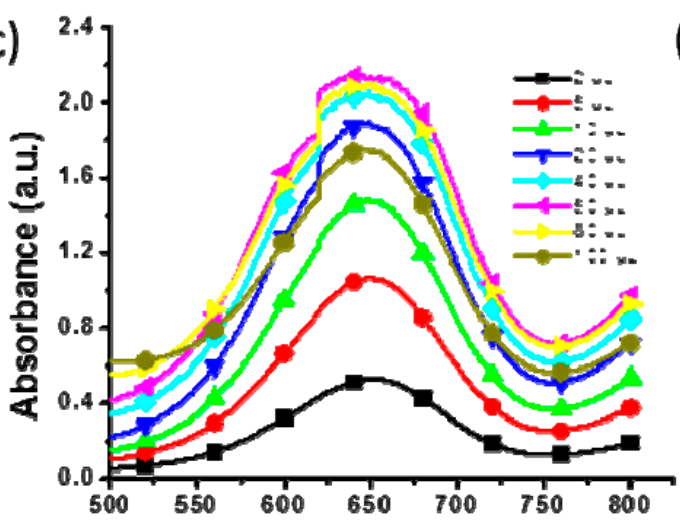

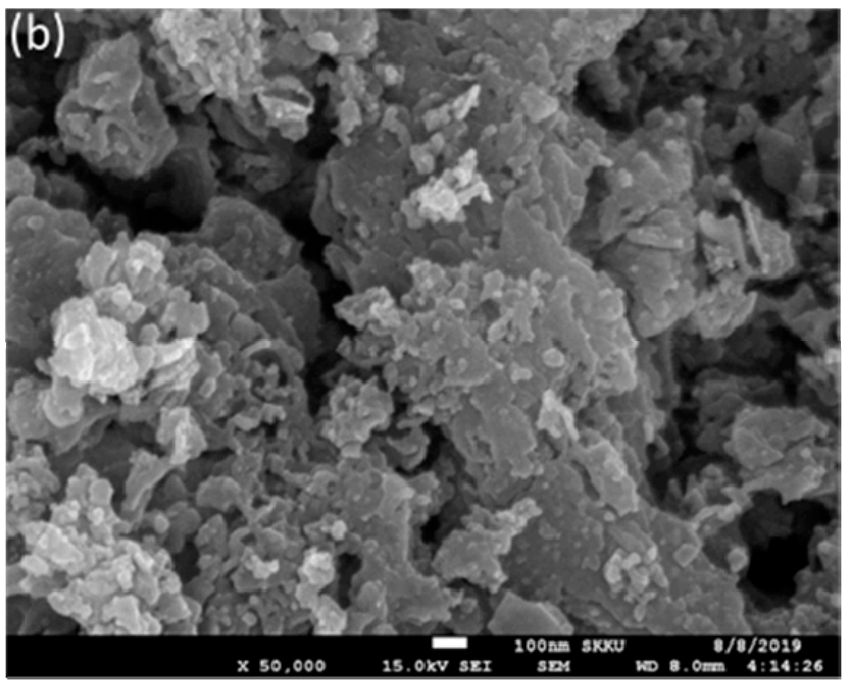

(d)

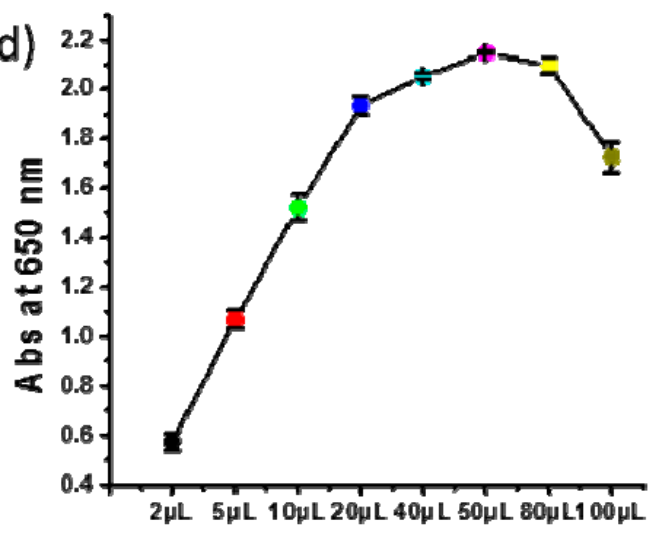

Figure 6. Cont. 

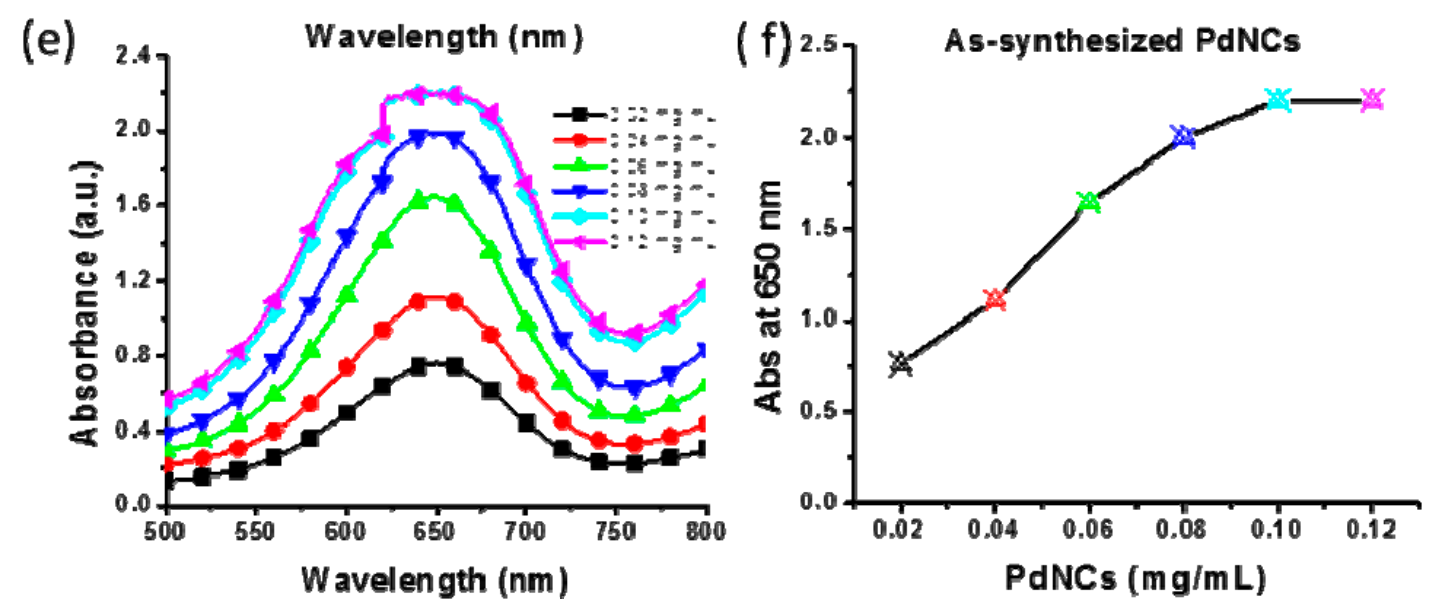

Figure 6. Effect of the nanocluster concentration: (a) Cuvettes showing the effect of the nanocluster concentration on the color intensity; (b) Scanning electron microscopy (SEM) micrograph of freeze-dried nanoclusters; (c) Absorbance spectra for various concentrations of as-synthesized PdNCs; (d) Triplicate experiments performed on the effect of varying the concentration of as-synthesized nanoclusters to produce error bars representing the standard deviations; (e) Absorbance spectra at various concentrations of freeze-dried nanoclusters; (f) Absorbance at $650 \mathrm{~nm}$ for assays having various concentrations of freeze-dried nanoclusters.

\subsection{Selectivity of Assay}

The selectivity of the assay was determined by exposing it to other relevant and interfering substances present in serum. The peroxidase mimetic activity of the nanoclusters possesses the specific characteristic of oxidizing TMB (colorless) into oxTMB (blue color) in the presence of $\mathrm{H}_{2} \mathrm{O}_{2}$. This feature of the assay can help easily distinguish $\mathrm{H}_{2} \mathrm{O}_{2}$ from various interfering substances in serum. Various interfering substances $\left(100 \mu \mathrm{M}\right.$ phenylalanine, cysteine, tryptophan, arginine, glucose, urea, $\mathrm{Na}^{+}$, $\mathrm{Fe}^{2+}, \mathrm{PO}_{4}{ }^{3-}, \mathrm{Mn}^{+2}, \mathrm{Ca}^{2+}, \mathrm{Mg}^{2+}, \mathrm{Zn}^{2+}, \mathrm{NH}_{4}{ }^{+}$, and $\mathrm{K}^{+}$) were included to evaluate the selectivity of the assay. Each interfering substance was assayed independently; when $\mathrm{H}_{2} \mathrm{O}_{2}$ was present in the sample, the nanoclusters would oxidize the TMB, the color of the assay changed rapidly from colorless to blue, and the UV/Vis spectra exhibited a strong peak at $650 \mathrm{~nm}$. Figure S5 shows that no peak was observed at $650 \mathrm{~nm}$ in the case of PdNCs, TMB, and TMB + PdNCs. We also performed the comparative analysis for TMB oxidation between biosynthesized PdNCs and leaf extract. Figure S6 shows that the strong absorbance was found at $650 \mathrm{~nm}$, only with nanocluster. Therefore, the leaf extract did not participate in the oxidation of TMB. The color change was only observed in the assays containing $\mathrm{H}_{2} \mathrm{O}_{2}$; the other interfering substances remained the same color as the blank assay. Figure 7 shows that high absorbance intensity was found only in the assays containing $\mathrm{H}_{2} \mathrm{O}_{2}$ as a strong color developed, whereas other interfering substances present in serum did not develop a blue color. This reveals that the assay is highly selective for $\mathrm{H}_{2} \mathrm{O}_{2}$. A quantitative analysis of the colorimetric assay was performed by comparing the absorbance of the sample and blank (Figure 7). This is significant for the determination of the intensity of the assay color, which represents the quantity of oxidized TMB. 


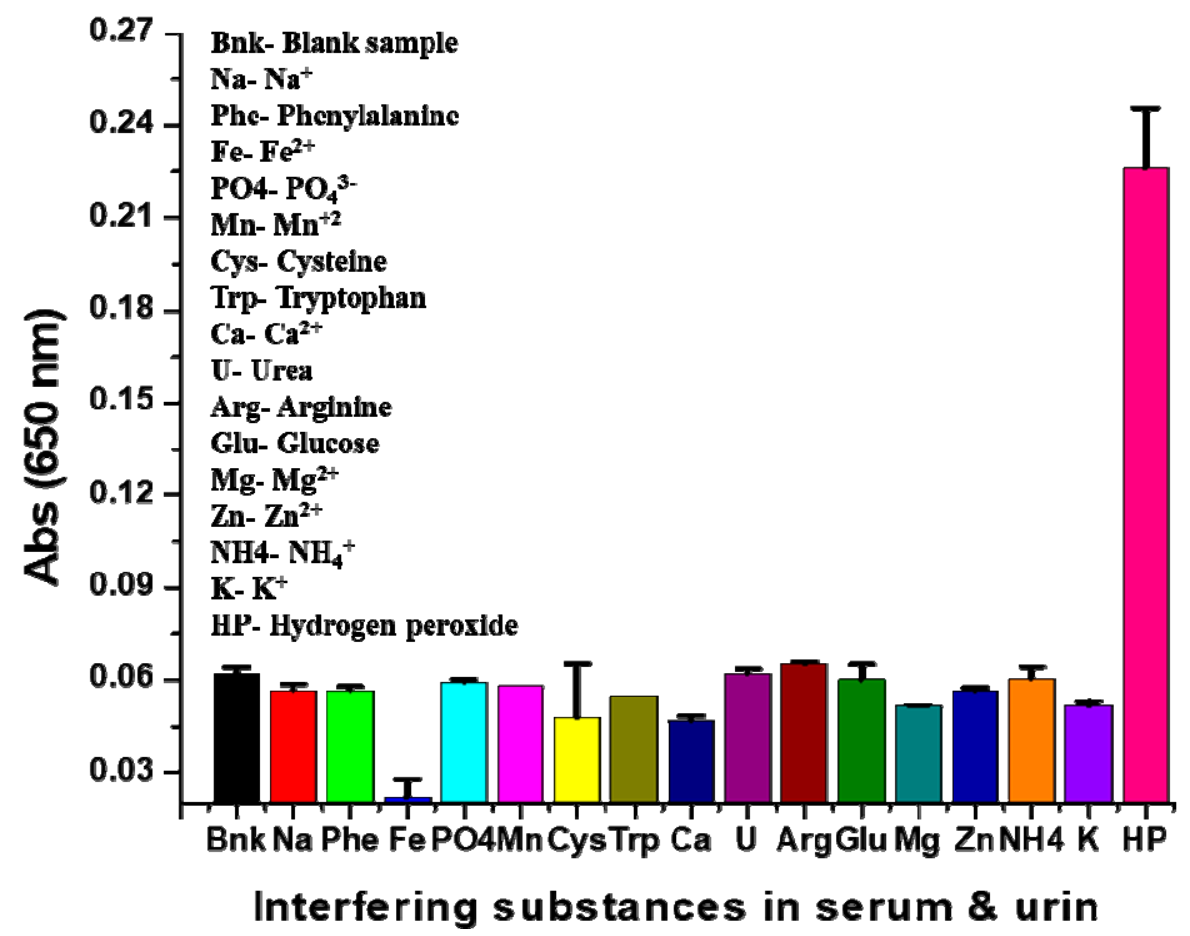

Figure 7. Selectivity of the assay for $\mathrm{H}_{2} \mathrm{O}_{2}$ detection: UV/Vis absorbance at $650 \mathrm{~nm}$ of various serum-interfering substances and performed triplicate experiments of the selectivity to produce error bars representing the standard deviations.

\subsection{Sensitivity of Assay}

The significance of the assay depends on its detection sensitivity at a lower concentration of target molecules. The assay sensitivity was evaluated through the detection of ultralow concentrations of $\mathrm{H}_{2} \mathrm{O}_{2}$ in a sample. Various $\mathrm{H}_{2} \mathrm{O}_{2}$ concentrations were used $(0.0625-100 \mu \mathrm{M})$ to determine the sensitivity by measuring the absorbance of the assay. The existence of $\mathrm{H}_{2} \mathrm{O}_{2}$ in the sample facilitated the oxidation of the chromogenic peroxidase substrate TMB and provided a blue color to the assay owing to the formation of oxTMB. It was observed that the absorbance at $650 \mathrm{~nm}$ increased with increasing $\mathrm{H}_{2} \mathrm{O}_{2}$ concentration. All the assays were incubated at room temperature $\left(22^{\circ} \mathrm{C}\right)$ for $20 \mathrm{~min}$, which was determined to be the optimum incubation time. Figure 8 shows that the lowest detected concentration was $0.0625 \mu \mathrm{M}$, as the absorbance is higher than that of the blank sample at $650 \mathrm{~nm}$. The color intensity of the assay increased with the increasing concentration of $\mathrm{H}_{2} \mathrm{O}_{2}$, and the absorbance at $650 \mathrm{~nm}$ increased with the increasing intensity of the assay color. The oxidation of TMB was quantitatively determined by considering the absorbance; the absorbance at $650 \mathrm{~nm}$ versus the $\mathrm{H}_{2} \mathrm{O}_{2}$ concentrations was plotted to quantify the oxidation of TMB (Figure 8). The assay exhibited a linear response at low $\mathrm{H}_{2} \mathrm{O}_{2}$ concentrations of 5 to $50 \mu \mathrm{M}$, and a linear regression correlation coefficient of 0.99424 was obtained (Figure 8 inset). The sensitivity response of assay was evaluated up to $100 \mu \mathrm{M} \mathrm{H}_{2} \mathrm{O}_{2}$. The lowest $\mathrm{H}_{2} \mathrm{O}_{2}$ concentration that could be detected by the naked eye through the assay color was found to be $40 \mu \mathrm{M}$. The results show that the proposed method has a good response at lower concentrations and a lower detection limit compared with those of previously reported methods (Table 1). Therefore, the proposed colorimetric assay is an ultrasensitive and selective method. 


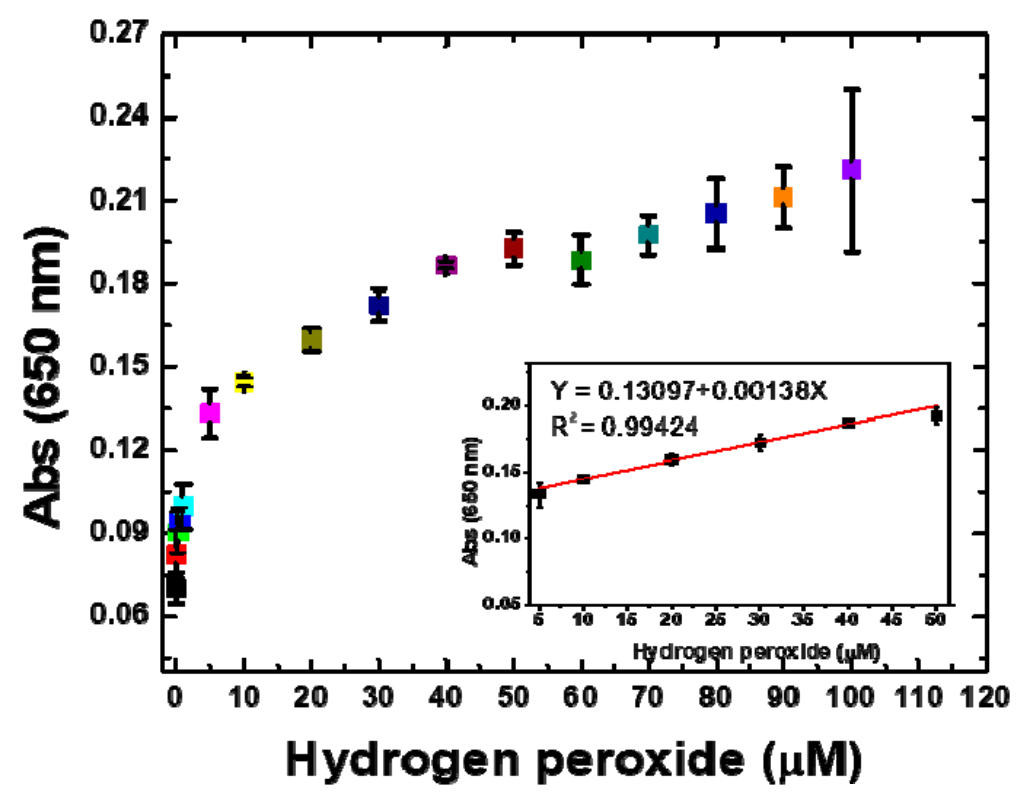

Figure 8. Sensitivity of the assay for $\mathrm{H}_{2} \mathrm{O}_{2}$ detection: UV/Vis absorbance values at $650 \mathrm{~nm}$ vs. $\mathrm{H}_{2} \mathrm{O}_{2}$ concentration $(0.0625-100 \mu \mathrm{M})$; the assay exhibited a linear response at low concentrations.

\section{Materials and Methods}

\subsection{Materials}

Palladium(II) chloride was purchased from Sigma-Aldrich (St. Louis, MO, USA) and used as a precursor for the synthesis of PdNCs. The chromogenic substrate 3,3',5,5'-tetramethylbenzidine (TMB) was also obtained from Sigma-Aldrich (St. Louis, MO, USA) for evaluation of the peroxidase mimetic activity of PdNCs. Hydrogen peroxide $\left(\mathrm{H}_{2} \mathrm{O}_{2}\right)$ was purchased from Samchun Chemical Co. Ltd. (Seoul, South Korea). L- arginine, cysteine, L- tryptophan, and L- phenylalanine were purchased from Sigma-Aldrich (St. Louis, MO, USA). All other chemicals, including sodium chloride, iron chloride tetrahydrate, potassium phosphate dibasic, magnesium chloride, calcium chloride, magnesium nitrate hexahydrate, zinc acetate dehydrate, ammonium sulfate, potassium chloride, urea, and glucose, were of analytical-grade and were used as received without further purification. Deionized water was used in all the experiments related to the biosynthesis of nanoparticles and catalytic oxidation of TMB.

\subsection{Preparation of Leaf Extract}

Fresh leaves of Erigeron Canadensis L. were collected from the campus of Sungkyunkwan University (Suwon, Gyeonggido, Republic of Korea) (Figure 1a). The leaves were washed several times with distilled water and dried at ambient temperature to remove the water from the surface of the leaves. Then, $8.5 \mathrm{~g}$ of chopped leaves was dispersed into $100 \mathrm{~mL}$ of deionized water in a $200 \mathrm{~mL}$ Erlenmeyer flask and placed on a magnetic stirrer at 500 revolutions per min (rpm) while the dispersion was boiled. Subsequently, the aqueous solution was allowed to cool at room temperature and was filtered through Whatman filter paper, yielding the required leaf extract. The extract was stored at $4{ }^{\circ} \mathrm{C}$ for use in the biosynthesis of PdNCs.

\subsection{Biosynthesis of Nanoclusters}

Palladium chloride $(2.5 \mathrm{mM})$ was dissolved in $20 \mathrm{~mL}$ of deionized water and placed on a magnetic stirrer for $1 \mathrm{~h}$ at ambient temperature and $600 \mathrm{rpm}$; the magnetic stirrer temperature was maintained at $85{ }^{\circ} \mathrm{C}$. Then, $1 \mathrm{~mL}$ of the as-prepared aqueous solution of the leaf extract was added drop by drop, followed by stirring under the same conditions for $180 \mathrm{~min}$. The bio-reduction of Pd(II) to $\mathrm{Pd}(0)$ was clearly indicated by a color change from light yellow-brown to a dark brownish color. 
The biosynthesized nanoclusters were analyzed by measuring the absorbance of the colloidal solution as a function of time.

\subsection{Characterization of Nanoclusters}

The biosynthesized PdNCs were characterized by ultraviolet-visible (UV/Vis) spectroscopy (UH-5300, Hitachi, Japan) in the scanning range of 300-800 $\mathrm{nm}$. The size distribution profile of the PdNCs was analyzed via dynamic light scattering (DLS; Zetasizer Nano S90, Malvern). Fourier transform infrared (FTIR) spectroscopy (FTS 7000, Varian, Australia) was performed to elucidate the role of biological molecules in the synthesis of nanoclusters. The morphology, size, d-spacing (inter-atomic spacing), and crystalline nature of the PdNCs were characterized via transmission electron microscopy (TEM; JEM-3010, JEOL, Japan). Meanwhile, the elemental composition of the nanoclusters was identified via energy-dispersive $X$-ray spectroscopy (EDX). The X-ray diffraction patterns were determined with an X-ray Diffractometer (X'Pert PRO, PANanalytical, Netherland) with $\mathrm{CuK} \alpha$ radiation $(\lambda=1.5417 \AA)$. The freeze-dried nanoclusters were further analyzed using scanning electron microscopy (SEM; Zeiss, EVO 18, Germany). The oxidation state of the PdNCs was evaluated using X-ray photoelectron spectroscopy (XPS; Thermo Scientific, UK).

\subsection{Colorimetric Detection}

The peroxidase mimetic activity of as-synthesized PdNCs was investigated through the catalytic oxidation of the peroxidase substrate TMB. The working solution of $\mathrm{H}_{2} \mathrm{O}_{2}$ was freshly prepared by diluting $\mathrm{H}_{2} \mathrm{O}_{2}(34.5 \% / \mathrm{d}-1.135)$ with deionized water. In a typical reaction (total volume: $1 \mathrm{~mL}$ ), $0.525 \mathrm{mM}(5 \mu \mathrm{L})$ of TMB (stock solution prepared in DMSO), $20 \mathrm{mM}$ (up to $50 \mu \mathrm{L}$ from stock) of $\mathrm{H}_{2} \mathrm{O}_{2}$, and $10 \mu \mathrm{L}$ of as-synthesized PdNCs were combined; the final volume was reached by adding $0.1 \mathrm{M}$ acetate buffer. The assay solution was incubated for $20 \mathrm{~min}$ at room temperature $\left(22^{\circ} \mathrm{C}\right)$. The TMB- $\mathrm{H}_{2} \mathrm{O}_{2}$ chromogenic reaction was evaluated by measuring the absorption peak at $650 \mathrm{~nm}$.

\subsection{Effect of PdNCs' Concentration}

In these experiments, the concentration of a colloidal solution of as-synthesized PdNCs varied in the range of 2 to $100 \mu \mathrm{L}(0.0005-0.025 \mathrm{mg} / \mathrm{mL})$. The reaction was performed in a total volume of $1 \mathrm{~mL}$ composed of $0.525 \mathrm{mM}(5 \mu \mathrm{L}) \mathrm{TMB}$ (stock solution prepared in DMSO), $20 \mathrm{mM}$ ( $50 \mu \mathrm{L}$ from stock) $\mathrm{H}_{2} \mathrm{O}_{2}$, and varying concentration of as-synthesized nanoclusters. The freeze-dried powder of the nanoclusters was also used to analyze the impact of concentration. A range of powder samples $(0.02-12 \mathrm{mg} / \mathrm{mL})$ was added to the reaction. The obtained results were compared to determine the conditions for the nanoclusters in terms of their stability and concentration impact.

\subsection{Selectivity of Assay}

The selectivity of the assay against various serum-interfering substances was investigated using $100 \mu \mathrm{M}$ of phenylalanine, cysteine, tryptophan, arginine, glucose, urea, $\mathrm{Na}^{+}, \mathrm{Fe}^{2+}, \mathrm{PO}_{4}{ }^{3-}, \mathrm{Mn}^{+2}$, $\mathrm{Ca}^{2+}, \mathrm{Mg}^{2+}, \mathrm{Zn}^{2+}, \mathrm{NH}_{4}{ }^{+}$, and $\mathrm{K}^{+}$. The color change of the assay was examined with respect to $\mathrm{H}_{2} \mathrm{O}_{2}$ visually. The assay was also analyzed by measuring its absorption from 500 to $800 \mathrm{~nm}$ by UV/Vis spectrophotometry. A quantitative analysis of the oxidation of the chromogenic substance TMB was performed by comparing the absorbance values at $650 \mathrm{~nm}$.

\subsection{Sensitivity of Assay}

The sensitivity of the assay was determined by determining the lowest detectable concentration of $\mathrm{H}_{2} \mathrm{O}_{2}$. The concentration of nanoclusters in the colloidal solution was estimated by freeze drying the colloidal solution; however, as-synthesized nanoclusters were applied in the assay. The working solution of $\mathrm{H}_{2} \mathrm{O}_{2}$ was freshly prepared by diluting $\mathrm{H}_{2} \mathrm{O}_{2}(34.5 \% / d-1.135)$ in deionized water. In a typical reaction (total volume $1 \mathrm{~mL}$ ), $0.525 \mathrm{mM} \mathrm{TMB}$ ( $5 \mu \mathrm{L}$ from a stock solution prepared in DMSO), 
varying concentrations of $\mathrm{H}_{2} \mathrm{O}_{2}$ (not more than $100 \mu \mathrm{L}$ from stock), and $10 \mu \mathrm{L}(0.0025 \mathrm{mg} / \mathrm{mL})$ of as-synthesized PdNCs were combined; the remaining volume was filled by adding $0.1 \mathrm{M}$ acetate buffer ( $\mathrm{pH}$ 5). The concentrations of $\mathrm{H}_{2} \mathrm{O}_{2}$ for the determination of the sensitivity of the colorimetric assay ranged from 0.0625 to $100 \mu \mathrm{M}$. A quantitative analysis of the $\mathrm{H}_{2} \mathrm{O}_{2}$ was performed by measuring the absorbance using a UV/Vis spectrophotometer. All the assays were incubated for $20 \mathrm{~min}$ at room temperature $\left(22^{\circ} \mathrm{C}\right)$.

\section{Conclusions}

In this study, we developed an unprecedented biological method for the synthesis of PdNCs using E. Canadensis L. leaf extract. This is the first report of the biological synthesis of nanoclusters. The Z-average diameter of the synthesized nanoclusters was found to be $64.47 \mathrm{~nm}$ by DLS, whereas a diameter of $55 \mathrm{~nm}$ was obtained by TEM because the DLS analysis showed the hydrodynamic size of the nanostructures. The synthesized nanoclusters were found to be significantly stable with a narrow size distribution. Nanoclusters were demonstrated to possess peroxidase mimetic activity that could oxidize a 3,3',5,5'-tetramethylbenzidine (TMB) peroxidase substrate. The assay was shown to exhibit a sufficient signal at an ultralow concentration of $0.0625 \mu \mathrm{M} \mathrm{H}_{2} \mathrm{O}_{2}$. Therefore, the developed assay provides an easy-to-use platform for the detection of $\mathrm{H}_{2} \mathrm{O}_{2}$ for clinical purposes.

Supplementary Materials: The following are available online at http://www.mdpi.com/1420-3049/25/15/3349/s1, Figure S1: Size distribution profile of biosynthesized nanoclusters, Figure S2. Various magnifications of TEM micrographs of PdNCs obtained after sonication of colloidal solution of nanoclusters for assessing their stability, Figure S3. DLS obtained after sonication of colloidal solution of nanoclusters for assessing their stability, Figure S4. Results for the control assay (without $\mathrm{H}_{2} \mathrm{O}_{2}$ ) showing absorbance at $650 \mathrm{~nm}$ in response to the addition of varying amounts of as-synthesized nanoclusters. Inset cuvettes show impact of nanocluster concentration on intensity of color without $\mathrm{H}_{2} \mathrm{O}_{2}$, Figure S5. Absorbance spectra of $0.525 \mathrm{mM}$ TMB, $10 \mu \mathrm{L}$ nanoclusters, and the combination of both; the inset cuvettes show the color, Figure S6. Comparative analysis for TMB oxidation between biosynthesized PdNCs and leaf extract; Table S1: Elemental compositions of PdNCs obtained with EDX analysis.

Author Contributions: S.J.C. developed the study concept and contributed to study design. R.M.T. performed the experiments related to the green synthesis of palladium nanoclusters and the sample characterization. S.J.C. and R.M.T. analyzed the UV-vis spectroscopy, DLS, XPS, XRD, FTIR, TEM, EDX, and FESEM results. R.M.T. performed the peroxidase mimetic activity of palladium nanoclusters and detection of hydrogen peroxide. S.J.C. supervised the whole study. S.J.C. and R.M.T. analyzed and discussed the results thoroughly and contributed to the final version of the manuscript. All authors have read and agreed to the published version of the manuscript.

Funding: This research was supported by the Bio and Medical Technology Development Program of the National Research Foundation (NRF) funded by the Korean government (MSIT) (NRF-2012M3A9C4048775 and NRF-2017M3A9C8031995).

Acknowledgments: All authors are thankful to the Cooperative Center for Research Facilities, Sungkyunkwan University, for providing an excellent facility for the characterization of the nanosheets. The manuscript has been edited carefully by a native-English-speaking professional editor from Editage, a division of Cactus Communications.

Conflicts of Interest: The authors declare that they have no competing interests.

\section{References}

1. Genet, J.-P. Asymmetric catalytic hydrogenation. Design of new ru catalysts and chiral ligands: From laboratory to industrial applications. Acc. Chem. Res. 2003, 36, 908-918. [CrossRef] [PubMed]

2. Behrens, M.; Studt, F.; Kasatkin, I.; Kühl, S.; Hävecker, M.; Abild-Pedersen, F.; Zander, S.; Girgsdies, F.; Kurr, P.; Kniep, B.-L. The active site of methanol synthesis over $\mathrm{Cu} / \mathrm{ZnO} / \mathrm{Al}_{2} \mathrm{O}_{3}$ industrial catalysts. Science 2012, 336, 893-897. [CrossRef] [PubMed]

3. Huang, Y.; Ren, J.; Qu, X. Nanozymes: Classification, catalytic mechanisms, activity regulation, and applications. Chem. Rev. 2019, 119, 4357-4412. [CrossRef] [PubMed]

4. Tripathi, R.M.; Ahn, D.; Kim, Y.M.; Chung, S.J. Enzyme mimetic activity of zno-pd nanosheets synthesized via a green route. Molecules 2020, 25, 2585. [CrossRef] [PubMed] 
5. Liang, M.; Fan, K.; Pan, Y.; Jiang, H.; Wang, F.; Yang, D.; Lu, D.; Feng, J.; Zhao, J.; Yang, L.; et al. Fe $\mathrm{F}_{3} \mathrm{O}_{4}$ magnetic nanoparticle peroxidase mimetic-based colorimetric assay for the rapid detection of organophosphorus pesticide and nerve agent. Anal. Chem. 2013, 85, 308-312. [CrossRef]

6. Darabdhara, G.; Sharma, B.; Das, M.R.; Boukherroub, R.; Szunerits, S. Cu-ag bimetallic nanoparticles on reduced graphene oxide nanosheets as peroxidase mimic for glucose and ascorbic acid detection. Sens. Actuators B Chem. 2017, 238, 842-851. [CrossRef]

7. Chen, W.H.; Vázquez-González, M.; Kozell, A.; Cecconello, A.; Willner, I. Cu ${ }^{2+}$-modified metal-organic framework nanoparticles: A peroxidase-mimicking nanoenzyme. Small 2018, 14, 1703149. [CrossRef]

8. Wang, X.; Zhao, X. Contribution of oxidative damage to antimicrobial lethality. Antimicrob. Agents Chemother. 2009, 53, 1395-1402. [CrossRef]

9. Nita, M.; Grzybowski, A. The role of the reactive oxygen species and oxidative stress in the pathomechanism of the age-related ocular diseases and other pathologies of the anterior and posterior eye segments in adults. Oxidative Med. Cell. Longev. 2016. [CrossRef]

10. Finkel, T.; Serrano, M.; Blasco, M.A. The common biology of cancer and ageing. Nature 2007, 448, 767-774. [CrossRef]

11. Inoguchi, T.; Li, P.; Umeda, F.; Yu, H.Y.; Kakimoto, M.; Imamura, M.; Aoki, T.; Etoh, T.; Hashimoto, T.; Naruse, M.; et al. High glucose level and free fatty acid stimulate reactive oxygen species production through protein kinase $\mathrm{C}$-dependent activation of $\mathrm{NAD}(\mathrm{P}) \mathrm{H}$ oxidase in cultured vascular cells. Diabetes 2000, 49, 1939-1945. [CrossRef] [PubMed]

12. Andersen, J.K. Oxidative stress in neurodegeneration: Cause or consequence? Nat. Med. 2004, 10, S18-S25. [CrossRef] [PubMed]

13. Park, L.; Zhou, P.; Pitstick, R.; Capone, C.; Anrather, J.; Norris, E.H.; Younkin, L.; Younkin, S.; Carlson, G.; McEwen, B.S.; et al. Nox2-derived radicals contribute to neurovascular and behavioral dysfunction in mice overexpressing the amyloid precursor protein. Proc. Natl. Acad. Sci. USA 2008, 105, 1347-1352. [CrossRef] [PubMed]

14. Tripathi, R.M.; Park, S.H.; Kim, G.; Kim, D.H.; Ahn, D.; Kim, Y.M.; Kwon, S.J.; Yoon, S.Y.; Kang, H.J.; Chung, S.J. Metal-induced redshift of optical spectra of gold nanoparticles: An instant, sensitive, and selective visual detection of lead ions. Int. Biodeterior. Biodegrad. 2019, 144, 104740. [CrossRef]

15. Tripathi, R.; Yoon, S.-Y.; Ahn, D.; Chung, S.J. Facile synthesis of triangular and hexagonal anionic gold nanoparticles and evaluation of their cytotoxicity. Nanomaterials 2019, 9, 1774. [CrossRef]

16. Sriramulu, M.; Sumathi, S. Biosynthesis of palladium nanoparticles using saccharomyces cerevisiae extract and its photocatalytic degradation behaviour. Adv. Nat. Sci. Nanosci. Nanotechnol. 2018, 9, 025018. [CrossRef]

17. Wang, W.; Zhang, B.; Liu, Q.; Du, P.; Liu, W.; He, Z. Biosynthesis of palladium nanoparticles using shewanella loihica PV-4 for excellent catalytic reduction of chromium (VI). Environ. Sci. Nano 2018, 5, 730-739. [CrossRef]

18. Tripathi, R.; Chung, S.J. Reclamation of hexavalent chromium using catalytic activity of highly recyclable biogenic Pd (0) nanoparticles. Sci. Rep. 2020, 10, 1-14. [CrossRef]

19. Tripathi, R.M.; Kumar, N.; Bhadwal, A.S.; Gupta, R.K.; Shrivastav, B.R.; Shrivastav, A. Facile and rapid biomimetic approach for synthesis of hap nanofibers and evaluation of their photocatalytic activity. Mater. Lett. 2015, 140, 64-67. [CrossRef]

20. Lin, W.Z.; Yeung, C.Y.; Liang, C.K.; Huang, Y.H.; Liu, C.C.; Hou, S.Y. A colorimetric sensor for the detection of hydrogen peroxide using DNA-modified gold nanoparticles. J. Taiwan Inst. Chem. Eng. 2018, 89, 49-55. [CrossRef]

21. Wang, B.; Ju, P.; Zhang, D.; Han, X.; Zheng, L.; Yin, X.; Sun, C. Colorimetric detection of $\mathrm{H}_{2} \mathrm{O}_{2}$ using flower-like $\mathrm{Fe}_{2}\left(\mathrm{MoO}_{4}\right)_{3}$ microparticles as a peroxidase mimic. Microchim. Acta 2016, 183, 3025-3033. [CrossRef]

22. Zong, C.; Wang, M.; Li, B.; Liu, X.; Zhao, W.; Zhang, Q.; Liang, A.; Yu, Y. Sensing of hydrogen peroxide and glucose in human serum via quenching fluorescence of biomolecule-stabilized au nanoclusters assisted by the fenton reaction. RSC Adv. 2017, 7, 26559-26565. [CrossRef]

23. Wang, Y.; Zhou, B.; Wu, S.; Wang, K.; He, X. Colorimetric detection of hydrogen peroxide and glucose using the magnetic mesoporous silica nanoparticles. Talanta 2015, 134, 712-717. [CrossRef] [PubMed]

24. Yuan, J.; Cen, Y.; Kong, X.J.; Wu, S.; Liu, C.L.; Yu, R.Q.; Chu, X. $\mathrm{MnO}_{2}$-nanosheet-modified upconversion nanosystem for sensitive turn-on fluorescence detection of $\mathrm{H}_{2} \mathrm{O}_{2}$ and glucose in blood. ACS Appl. Mater. Interfaces 2015, 7, 10548-10555. [CrossRef] 
25. Liu, Q.; Jiang, Y.; Zhang, L.; Zhou, X.; Lv, X.; Ding, Y.; Sun, L.; Chen, P.; Yin, H. The catalytic activity of ag2s-montmorillonites as peroxidase mimetic toward colorimetric detection of $\mathrm{H}_{2} \mathrm{O}_{2}$. Mater. Sci. Eng. C 2016, 65, 109-115. [CrossRef]

26. Singh, V.K.; Yadav, P.K.; Chandra, S.; Bano, D.; Talat, M.; Hasan, S.H. Peroxidase mimetic activity of fluorescent ns-carbon quantum dots and their application in colorimetric detection of $\mathrm{H}_{2} \mathrm{O}_{2}$ and glutathione in human blood serum. J. Mater. Chem. B 2018, 6, 5256-5268. [CrossRef]

27. Zhang, W.; Liu, W.; Li, P.; Huang, F.; Wang, H.; Tang, B. Rapid-response fluorescent probe for hydrogen peroxide in living cells based on increased polarity of C-B bonds. Anal. Chem. 2015, 87, 9825-9828. [CrossRef]

28. Wu, G.; Zeng, F.; Yu, C.; Wu, S.; Li, W. A ratiometric fluorescent nanoprobe for $\mathrm{H}_{2} \mathrm{O}_{2}$ sensing and in vivo detection of drug-induced oxidative damage to the digestive system. J. Mater. Chem. B 2014, 2, 8528-8537. [CrossRef]

29. Zong, C.; Li, B.; Wang, J.; Liu, X.; Zhao, W.; Zhang, Q.; Nie, X.; Yu, Y. Visual and colorimetric determination of $\mathrm{H}_{2} \mathrm{O}_{2}$ and glucose based on citrate-promoted $\mathrm{H}_{2} \mathrm{O}_{2}$ sculpturing of silver nanoparticles. Microchim. Acta 2018, 185, 199. [CrossRef]

30. Zhang, X.; Wu, Z.; Liu, F.; Fu, Q.; Chen, X.; Xu, J.; Zhang, Z.; Huang, Y.; Tang, Y.; Guo, T.; et al. Hydrogen peroxide and glucose concentration measurement using optical fiber grating sensors with corrodible plasmonic nanocoatings. Biomed. Opt. Express 2018, 9, 1735-1744. [CrossRef]

31. Zhang, L.; Li, L. Colorimetric detection of hydrogen peroxide using silver nanoparticles with three different morphologies. Anal. Methods 2016, 8, 6691-6695. [CrossRef]

32. Yang, H.; Yang, R.; Zhang, P.; Qin, Y.; Chen, T.; Ye, F. A bimetallic (Co/2Fe) metal-organic framework with oxidase and peroxidase mimicking activity for colorimetric detection of hydrogen peroxide. Microchim. Acta 2017, 184, 4629-4635. [CrossRef]

33. Sodzel, D.; Khranovskyy, V.; Beni, V.; Turner, A.P.; Viter, R.; Eriksson, M.O.; Holtz, P.O.; Janot, J.M.; Bechelany, M.; Balme, S.; et al. Continuous sensing of hydrogen peroxide and glucose via quenching of the UV and visible luminescence of ZnO nanoparticles. Microchim. Acta 2015, 182, 1819-1826. [CrossRef]

34. Danaei, M.; Dehghankhold, M.; Ataei, S.; Hasanzadeh Davarani, F.; Javanmard, R.; Dokhani, A.; Khorasani, S.; Mozafari, M.R. Impact of particle size and polydispersity index on the clinical applications of lipidic nanocarrier systems. Pharmaceutics 2018, 10, 57. [CrossRef]

35. Malvern Instruments Ltd. Inform White Paper Dynamic Light Scattering; Malvern Instruments Ltd.: Malvern, UK, 2011; pp. 1-6.

36. Stolyarov, I.P.; Gaugash, Y.V.; Kryukova, G.N.; Kochubei, D.I.; Vargaftik, M.N.; Moiseev, I.I. New palladium nanoclusters. Synthesis, structure, and catalytic properties. Russ. Chem. Bull. 2004, 53, 1194-1199. [CrossRef]

37. Li, X.; Goh, T.W.; Xiao, C.; Stanton, A.L.; Pei, Y.; Jain, P.K.; Huang, W. Synthesis of monodisperse palladium nanoclusters using metal-organic frameworks as sacrificial templates. ChemNanoMat 2016, 2, 810-815. [CrossRef]

38. Tripathi, R.M.; Gupta, R.K.; Bhadwal, A.S.; Singh, P.; Shrivastav, A.; Shrivastav, B.R. Shrivastav. Fungal biomolecules assisted biosynthesis of $\mathrm{Au}-\mathrm{Ag}$ alloy nanoparticles and evaluation of their catalytic property. IET Nanobiotechnol. 2015, 9, 178-183. [CrossRef]

39. Abboud, Y.; Eddahbi, A.; El Bouari, A.; Aitenneite, H.; Brouzi, K.; Mouslim, J. Microwave-assisted approach for rapid and green phytosynthesis of silver nanoparticles using aqueous onion (Allium cepa) extract and their antibacterial activity. J. Nanostruct. Chem. 2013, 3, 84. [CrossRef]

40. Jyoti, K.; Baunthiyal, M.; Singh, A. Characterization of silver nanoparticles synthesized using urtica dioica linn. Leaves and their synergistic effects with antibiotics. J. Radiat. Res. Appl. Sci. 2016, 9, 217-227. [CrossRef]

41. Li, X.; Yang, M.; Han, Y.-F.; Gao, K. New sesquiterpenes from erigeron annus. Planta Med. 2005, 71, $268-272$. [CrossRef]

42. Nazaruk, J.; Kalemba, D. Chemical composition of the essential oils from the roots of Erigeron acris L. and Erigeron annuus (L.) pers. Molecules 2009, 14, 2458-2465. [CrossRef] [PubMed]

43. Tripathi, R.; Chung, S.J. Biogenic nanomaterials: Synthesis, characterization, growth mechanism, and biomedical applications. J. Microbiol. Methods 2019, 157, 65-80. [CrossRef] [PubMed]

(C) 2020 by the authors. Licensee MDPI, Basel, Switzerland. This article is an open access article distributed under the terms and conditions of the Creative Commons Attribution (CC BY) license (http://creativecommons.org/licenses/by/4.0/). 